\title{
OSTEOGENESIS IMPERFECTA CONGENITA IN DIZYGOTIC TWINS
}

\author{
BY \\ M. M. ZEITOUN, A. H. IBRAHIM and A. S. KASSEM \\ From the Department of Paediatrics, Faculty of Medicine, Alexandria University, Alexandria, Egypt, U.A.R.
}

(RECEIVED FOR PUBLICATION MAY 8, 1962)

Osteogenesis imperfecta is a disease characterized by increased fragility of the bones which are easily fractured by slight trauma. Patients suffering from this disorder usually have blue sclerae and flaccid ligaments; some of them become deaf later in life.

Scattered reports of this disorder date back at least to 1678 (quoted by Seedorff in 1949). Vrolik (1849) described the disease in the newborn infant.

Although osteogenesis imperfecta is a generalized bone disease that is present from birth, clinical and radiological features seem to differ quite prominently in the various age-groups. Luck (1950) divided it for the sake of clarity into four groups, according to the age of onset, but admitted that there was no clear-cut demarcation between them. These groups included: osteogenesis imperfecta congenitalis, infantis, tarda and adulta.

The first type 'osteogenesis imperfecta congenita' presents a characteristic clinical picture which represents the extreme examples of the disease. In this form, fracture deformities may occur in utero or the bones may break during parturition. Many of the cases of osteogenesis imperfecta congenita are stillborn or succumb shortly after birth.

Whereas the infantile, tarda and adulta types of the disease follow a dominant Mendelian trait, the hereditary aspects of osteogenesis imperfecta congenita are usually not considered to be prominent. Because of the early death of most infants with the congenital type of osteogenesis imperfecta, heredity does not usually appear to play an important role. Goldfarb and Ford (1954) for these reasons reported two consecutive female siblings with congenital osteogenesis imperfecta, one living to the age of 5 months and the other to approximately $5 \frac{1}{2}$ months. Both had evidence of fractures in intrauterine life, further fractures following birth, characteristic skull changes and blue sclerae. Recently, Awwaad and Reda (1960) described two similar cases of congenital osteogenesis imperfecta in one sibship. It thus appears very interesting to report on dizygotic twins with osteogenesis imperfecta congenita; to our knowledge, the first to be mentioned in the literature.

\section{Case Reports}

Case 1. The male twin aged 26 days was admitted to hospital on September 7, 1961, with the history since birth of excessive crying and irritability on minimal handling, together with marked deformities of the four extremities. He was born after a full-term normal pregnancy and labour, and intrauterine foetal movements had been detected by the mother during pregnancy.

Family history revealed consanguinity of the parents, who were second cousins, and the twins were their only children. Both parents are in perfect health and do not manifest any abnormality related to this disease in one form or the other. No history suggestive of osteogenesis imperfecta could be detected in any of their relatives.

Physical examination on admission revealed an underweight irritable infant with frequent powerful cry. The head was globular, circumference 14 in. $(35 \cdot 5 \mathrm{~cm}$.) with very marked softening of the cranial bones. The anterior and posterior fontanelles were wide and slightly tense. The eyes were bulging, and the sclerae blue. The heart was clinically free. There was bilateral wheeze and a small umbilical hernia. There were multiple healed fracture deformities of the four extremities and clavicles, giving the infant a characteristic appearance (Fig. 1). Mobility of the extremities was minimal, and when induced passively, they initiated excessive crying.

Radiograph taken on admission revealed a marked and typical radiological picture of osteogenesis imperfecta congenita (Fig. 2).

Laboratory findings on admission were as follows. $\mathrm{Hb}, 63 \%$; red blood cells, 3,000,000; white blood cells, 7,000 (polymorphs $34 \%$, lymphocytes $64 \%$, monocytes $2 \%$ ); urinalysis, normal; serum calcium $9 \cdot 2 \mathrm{mg} . / 100 \mathrm{ml}$., serum inorganic phosphorus, $4.5 \mathrm{mg} . / 100 \mathrm{ml}$.; serum alkaline phosphatase 30 K.A. units, and serum acid phosphatase 2 K.A. units.

In hospital, the infant developed repeated respiratory infections and died two and a half months after admission from bilateral bronchopneumonia, in spite of 


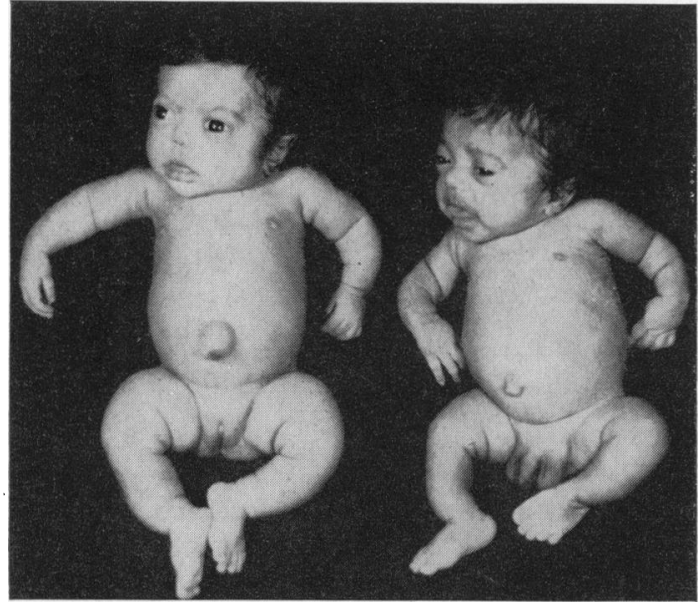

FIG. 1.-Both twins.

prolonged therapy with broad spectrum antibiotics and penicillin and streptomycin.

Autopsy revealed bilateral bronchopneumonia and the typical bone picture of osteogenesis imperfecta congenita with several generalized old and recent pathological fractures of the long bones and clavicles (Fig. 3).

Case 2. A female twin aged 26 days, was admitted to hospital on September 7, 1961, with the history since

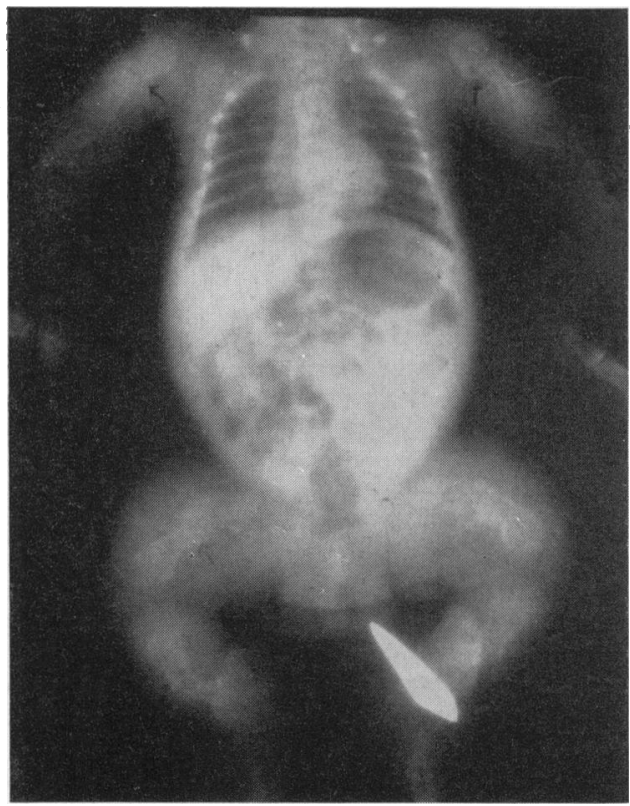

FIG. 2.-Radiograph of the male twin showing multiple fractures of the extremities and clavicles. birth of excessive crying and marked deformities of the four extremities, which had been noticed since birth.

Clinical examination on admission revealed an underweight irritable infant with the same clinical findings as her twin brother, with a big imbilical hernia (Fig. 1).

Radiograph taken on admission revealed a typical picture of osteogenesis imperfecta congenita (Fig. 4).

Laboratory findings on admission were as follows. $\mathrm{Hb}, 65 \%$; red blood cells, 3,200,000; white blood cells, 7,500 (polymorphs $40 \%$, lymphocytes $59 \%$, monocytes $1 \%$ ); urinalysis, normal; serum calcium $9.7 \mathrm{mg} . / 100 \mathrm{ml}$., serum inorganic phosphorus $4.1 \mathrm{mg} . / 100 \mathrm{ml}$; serum alkaline phosphatase 39 K.A. units, and serum acid phosphatase 2 K.A. units.

In hospital she developed repeated attacks of bronchopneumonia for which antibiotics were given. She was discharged after the death of her twin brother, with a normal chest, but returned after 15 days, with bronchopneumonia, and died in hospital one month later in spite of antibiotics.

Autopsy revealed bronchopneumonia and the typical bony picture of osteogenesis imperfecta congenita (Fig. 3).

Investigation of Parents. Both parents were examined clinically for any evidence of healed fractures, for deafness or blue sclerae, but they were found to be normal.

Radiological examination of the long bones did not reveal any abnormality.

\section{Discussion}

This report describes two classical cases of osteogenesis imperfecta congenita in twins, to our knowledge the first to be reported in the literature at our disposal. The literature mentions only a few cases reported in the same sibship (Goldfarb and Ford, 1954; Awwaad and Reda, 1960). Although of different sex, there is no difficulty in classifying these twins as dizygotic.

Unfortunately this report does not clarify the controversial problem of the mode of inheritance in osteogenesis imperfecta congenita. Bell (1928), Fuss (1935) and Hills and McLanahan (1937) believe this disease is inherited as an autosomal dominant. Seedorff (1949) after studying 55 sibships with 180 affected individuals constructed a scheme based on the theories that each component of the syndrome of osteogenesis imperfecta was the result of a separate gene and that three separate genes controlled the bone fragility, mutation in the three collectively being responsible for osteogenesis imperfecta congenita. There are arguments against this multiple gene theory of inheritance, and frequently the statement appears that the so-called congenital form of the disease is not inherited in many instances or is inherited in a different manner (recessive) from the other forms (McKusick, 1956). The genetic analysis of the pedigrees reported by 
Smårs (1961) shows close agreement with the hypothesis that osteogenesis imperfecta is due primarily to a single heterozygous gene which expressivity may be complete or vary considerably. The parents of our cases were thoroughly investigated and no clinical or radiological evidence of any abnormality characteristic of the syndrome could be detected. Although this might argue against the disease being hereditary, yet severely affected stillborn children of normal parents may result from new mutations. On the other hand, even if the parents were considered normal by every test, a suspicion of hidden abnormality would remain. Smårs reported five sibships with two or more affected members who had unaffected parents. It is shown that recessive inheritance is unlikely. The most probable explanation is that the effect of the dominant gene may be occasionally completely suppressed. Although consanguinity in our cases is positive, yet it is likely that it has nothing to do with the condition. As the twin method (Metrakos, 1953) could be valuable in determining whether the disease under discussion is of a hereditary nature or not, provided a sufficient number of twins were available for analysis, it is hoped that further reports on osteogenesis imperfecta congenita in twins may clarify this point.

Alkaline phosphatase was repeatedly raised in both of our twins, a feature not mentioned in previously reported cases. A possible explanation for this high level of serum alkaline phosphatase could be the presence of multiple healing fractures.

\section{REFERENCES}

Awwaad, S. and Reda, M. (1960). Osteogenesis imperfecta. Arch. Pediat., 77, 280.

Bell, J. (1928). Treasury of Human Inheritance, Vol. 2, part 3. Cambridge University Press, Cambridge and London.

Fuss, H. (1935). Die erbliche Osteopsathyrose. Dtsch. Z. Chir., 245, 279.

Goldfarb, A. A. and Ford, D. (1954). Osteogenesis imperfecta congenita in consecutive siblings. J. Pediat., 44, 264.

Hills, R. G. and McLanahan, S. (1937). Brittle bones and blue scleras in five generations. Arch. intern. Med., 59, 41.

Luck, J. V. (1950). Bone and Joint Diseases, p. 382. Charles C. Thomas, Springfield, Illinois.

McKusick, A. V. (1956). Heritable disorders of connective tissue. V. Osteogenesis imperfecta. J. chron. Dis., 3, 180.

Metrakos, J. D. (1953). Congenital hypertrophic pyloric stenosis in twins. Arch. Dis. Childh., 28, 351 .

Seedorff, K. S. (1949). Osteogenesis Imperfecta. A Study of Clinical Features and Heredity. Based on 55 Danish Families Comprising 180 Affected Persons. Universitetsforlaget, Århus.

Smårs, G. (1961). Osteogenesis Imperfecta in Sweden: Clinical, Genetic, Epidemiological and Socio-Medical Aspects. ScandiGenetic, Epidemiological and Socio-M

Vrolik, W. (1849). Tabulae ad illustrandam embryogenesin hominis et mammalium, tam naturalem quam abnormen. G. M. P. Londonck, Amstelodami. Cited by J. Bell, 1928.

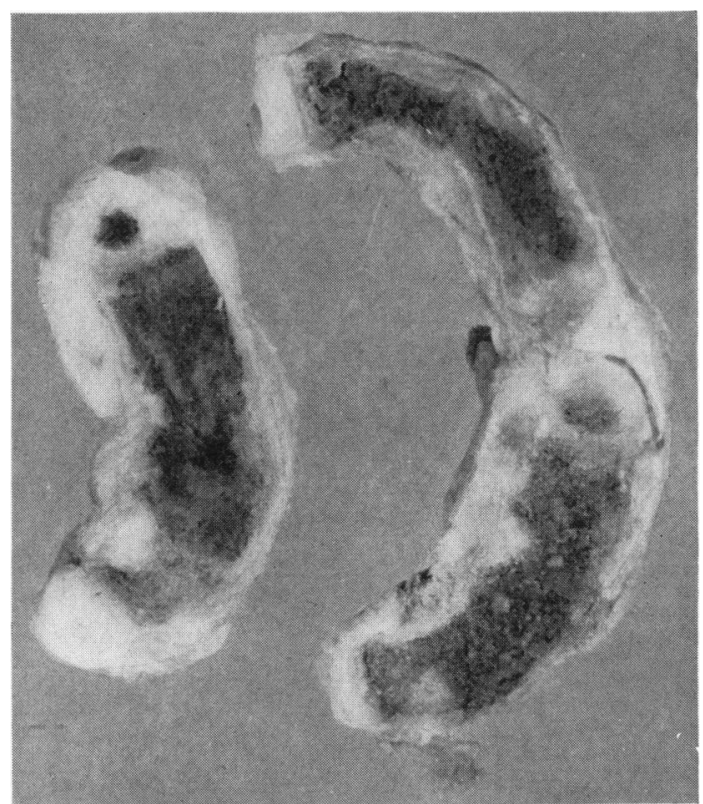

FIG. 3.-Longitudinal section of the bones of the lower extremities of both twins.

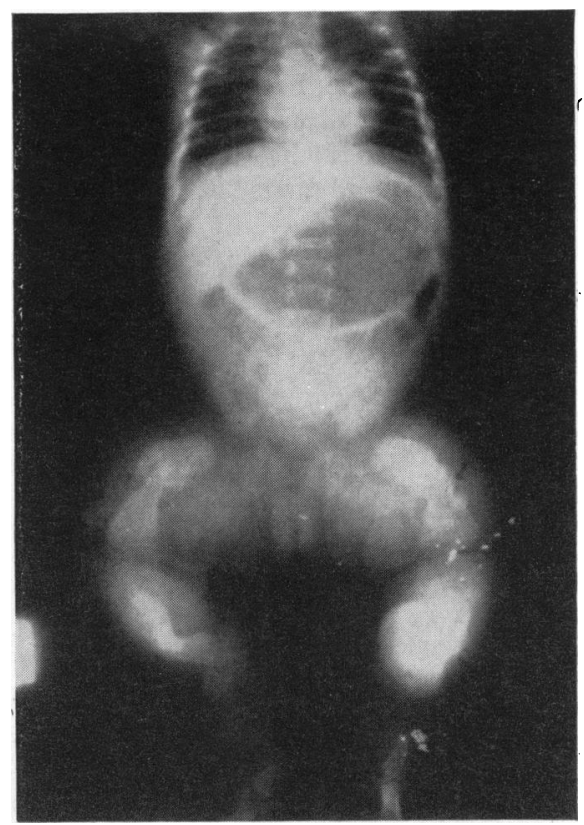

FIG. 4.-Radiograph of the female twin showing multiple fractures of the lower extremities. 